\title{
Caracterização e aceitação sensorial de frozen yogurt formulado com polpa de laranjinha de pacu (Pouteira glomerata (Miq.) Radlk) e culturas probióticas.
}

\author{
Characterization and sensorial acceptance of frozen yogurt formulated with Laranjinha de \\ pacu (Pouteira glomerata (Miq.) Radlk) and probiotic cultures.
}
Lívia Maria Serpa Nogueira ${ }^{1}$
Priscila Silva Figueiredo ${ }^{2}(*)$
Camila Jordão Candido 3
Luciana Miyagusku ${ }^{4}$
Raquel Pires Campos ${ }^{5}$
Priscila Aiko Hiane ${ }^{6}$

Rita de Cássia Avellaneda Guimarães ${ }^{7}$

Amauri Ernani Torres Aréco ${ }^{8}$

\section{RESUMO}

O objetivo deste trabalho foi elaborar e avaliar um frozen yogurt com polpa de laranjinha de pacu concentrada e culturas probióticas liofilizadas (Lactobacillus acidophilus e Bifidobacterium sp.). A composição físico-química da polpa de laranjinha de pacu e do produto elaborado foi determinada, assim como análise microbiológica e sensorial. Os teores de sólidos totais, proteínas e gordura do frozen yogurt encontrados estão de acordo com o estabelecido pela legislação vigente para gelados comestíveis. Em

1 Graduanda; Farmácia; Universidade Federal de Mato Grosso do Sul, UFMS, Brasil: Endereço: Cidade Universitária, Av. Costa e Silva - Pioneiros, Campo Grande - MS, 79070-900; E-mail: livia_serpa15@hotmail.com

2 Doutoranda; Saúde e Desenvolvimento; Região Centro-Oeste, Universidade Federal de Mato Grosso do Sul, UFMS, Brasil; professora colaboradora da Universidade Federal de Mato Grosso do Sul para os cursos de graduação em Farmácia, Nutrição e Tecnologia em Alimentos; Endereço: Cidade Universitária, Av. Costa e Silva - Pioneiros, Campo Grande MS, 79070-900; E-mail: pri.figueiredo92@gmail.com $\quad\left(^{*}\right)$ Autor para correspondências

3 Me.; Saúde e Desenvolvimento; Centro-Oeste, Universidade Federal de Mato Grosso do Sul, UFMS, Brasil; Técnica em Alimentos e Laticínios da UFMS atuando na área de ciência e tecnologia de alimentos, química dos alimentos e nutrição experimental. Professora colaboradora de bromatologia e bioquímica de alimentos; Endereço: Universidade Federal de Mato Grosso do Sul, Conselho de Pesquisa e Pós-Graduação da UFMS. Cidade Universitária 79070-900 - Campo Grande, MS - Brasil E-mail: cahjordao@gmail.com

4 Dra.; Tecnologia de Alimentos; Universidade Estadual de Campinas, UNICAMP, Brasil; Professora em pós -graduação, auditoria interna de Sistema da Qualidade e Diretora Técnica no Centro de Tecnologia de Carnes; Endereço: Universidade Federal de Mato Grosso do Sul. Cidade Universitária s/n Cidade Universitária, 79070-900 - Campo Grande, MS - Brasil E-mail: lumy597@gmail.com

5 Dra.; Agronomia; Universidade Estadual de Maringá, UEM, Brasil; Docente da Unidade de Tecnologia de Alimentos e Saúde Pública, com pesquisa e extensão envolvendo frutos do Cerrado e do Pantanal; Endereço: Universidade Federal de Mato Grosso do Sul, DTA/CCBS. Cidade Universitária, 79070-900 - Campo Grande, MS - Brasil; E-mail: raquel. campos@ufms.br

6 Dra.; Ciências da Saúde; Universidade de Brasília, UnB, Brasil; Professora Titular da Universidade Federal de Mato Grosso do Sul (UFMS); Endereço: Universidade Federal de Mato Grosso do Sul, Centro de Ciências Biológicas e da Saúde da UFMS, Departamento de Tecnologia de Alimentos e Saúde Pública. Cidade Universitária, Cidade Universitária 79070900 - Campo Grande, MS - Brasil E-mail: priscila.hiane@ufms.br

7 Dra.; Saúde e Desenvolvimento na Região Centro-Oeste; Universidade Federal de Mato Grosso do Sul, UFMS, Brasil; Professor Adjunto da Universidade Federal de Mato Grosso do Sul, UFMS, Brasil; Endereço: Universidade Federal de Mato Grosso do Sul, Faculdade de Ciências Farmacêuticas, Alimentos e Nutrição. Av. Costa e Silva Cidade Universitária 79070900 - Campo Grande, MS - Brasil; E-mail: rita.guimaraes@ufms.br

8 Graduado; Medicina Veterinária; Universidade Federal de Mato Grosso do Sul, UFMS, Brasil; Endereço: Universidade Federal de Mato Grosso do Sul, Faculdade de Ciências Farmacêuticas, Alimentos e Nutrição. Av. Costa e Silva Cidade Universitária 79070900 - Campo Grande, MS - Brasil; E-mail: amauri_ernani2432@hotmail.com 
relação à análise microbiológica, após 30 dias de armazenamento, o mesmo apresentou número de células viáveis necessárias para ser caracterizado como produto probiótico. Assim, o frozen yogurt formulado constitui-se em um alimento probiótico com alto valor nutricional e funcional, e índice de aceitabilidade superior a $80 \%$ nos atributos avaliados: sabor, aroma, textura e aparência.

Palavras-chave: Pouteira glomerata (Miq.) Radlk., alimento funcional, bactérias probióticas.

\section{ABSTRACT}

The objective of this study was to elaborate and evaluate a frozen yogurt containing a concentrated pulp of laranjinha de pacu and freeze-dried probiotic cultures (Lactobacillus acidophilus and Bifidobacterium sp.). The physical and chemical composition of the laranjinha de pacu pulp and of the elaborated product, which was subjected to microbiological and sensory analysis, was determined. The total solids, protein and fat content of the frozen yogurt are in accordance with the current legislation for edible ices. After 30 days of storage, the frozen yogurt presented the number of viable cells required so as to be characterized as a probiotic. Thus, the frozen yogurt is formulated in a probiotic food with high nutritional and functional value, and wide acceptance by sensory tasters represented by higher acceptance index of $80 \%$ in the evaluated attributes: taste, aroma, texture and appearanxce.

Key words: Pouteira glomerata (Miq.) Radlk., functional food, probiotic bacteria.

\section{INTRODUÇÃO}

Os alimentos funcionais vêm ganhando destaque nos últimos anos devido à maior busca pela alimentação saudável. Os efeitos responsáveis por seus benefícios são metabólicos e fisiológicos, capazes de fornecer melhor desempenho ao organismo pelo seu consumo regular (VIDAL et al., 2012; GUL; SINGH; JABEEN, 2015; SHARIF et al., 2018). Atuam por meio de ações no sistema nervoso central e periférico, como regulação de absorção e apetite, estando associados à prevenção de doenças relacionadas ao estilo de vida, como hipertensão, diabetes, câncer, hipercolesterolemia, anemia e agregação plaquetária, com redução da produção de espécies reativas de oxigênio (MITSUOKA, 2014).

Dentre os alimentos considerados funcionais, destacam-se aqueles constituídos de probióticos, que fornecem micro-organismos viáveis, em quantidades apropriadas. Os gêneros mais comumente usados em alimentos são os Lactobacillus e Bifidobacterium, que interagem com a microbiota intestinal inibindo patógenos entéricos e modulando o sistema imune (ROBERFROID et al., 2010; FERREIRA et al., 2014). Produtos alimentícios como os laticínios contribuem para a sobrevivência dos probióticos ao suco gástrico, particularmente por seu efeito tamponante e protetor (ROSS et al., 2005).

A alimentação tem efeito direto sobre a microbiota, que, em última análise, resultaria em mudanças em reações bioquímicas no lúmen intestinal (HEMARAJATA; VERSALOVIC, 2013).

Diversas espécies frutíferas do Cerrado constituem importantes fontes de exploração alimentar em virtude de seus atributos sensoriais (como aromas característicos e intensos, cor e 
sabor), elevados teores de vitaminas, minerais e fibras, repercutindo em ampla aceitação popular, que podem ser consumidos em sua forma in natura ou em produtos processados (ALMEIDA et al., 2011; CARDOSO et al., 2011). Além de suas qualidades nutricionais e versatilidade na sua utilização, os frutos nativos são potenciais fontes de interesse devido às possíveis contribuições para uso sustentável, conservação e relevância para a agroindústria (OLIVEIRA et al., 2008).

Dentre esses frutos, a laranjinha de pacu (Pouteria glomerata (Miq.) (Radlk.), distribui-se no Chaco Oriental e na mata ribeirinha do Pantanal, utilizada usualmente como alimento de peixe (isca de pacu). A polpa apresenta sabor ácido, porém, agradável, além de ser rica em vitamina $\mathrm{C}$, com potencial para comercialização e na elaboração de doces, sucos e sorvetes (DAMASCENO JUNIOR et al., 2010).

Dentre as possíveis alternativas de aproveitamento do fruto, tem-se o frozen yogurt, também chamado de sorvete de iogurte, caracterizado como um produto obtido basicamente com leite submetido à fermentação láctea, por meio da ação do Streptococcus thermophilus e Lactobacillus bulgaricus, ou a partir de iogurte com ou sem a adição de outras substâncias alimentícias, sendo posteriormente aerado e congelado (BRASIL, 2005). A fermentação prévia do leite confere melhor digestibilidade, além de melhorar a textura e o desenvolvimento do sabor, devido à acidificação que ocorre pela transformação dos açúcares em ácido láctico por ação dos microrganismos (CORTE, 2008; ROCHA et al., 2008).

A utilização de frutos nativos na elaboração de frozen yogurt constitui alternativa alimentar que pode contribuir para maior consumo do sorvete, associando o valor nutricional do iogurte com o sabor refrescante do sorvete, além de apresentar os benefícios das culturas probióticas, tornando-o um alimento rico nutricionalmente que valoriza os frutos nativos.

Este trabalho teve por objetivo elaborar um frozen yogurt com polpa de laranjinha de pacu (Pouteira glomerata (Miq.) Radlk.) e culturas probióticas (Bifidobacterium sp. e Lactobacillus acidophilus), a fim de avaliar sua qualidade físico-química, aceitação sensorial e a potencialidade probiótica durante o armazenamento.

\section{MATERIAL E MÉTODOS}

\section{Matéria-prima}

Frutos de laranjinha de pacu (Pouteria glomerata (Miq.) (Radlk.) foram adquiridos na região da Serra do Amolar, distrito do município de Corumbá, localizada no Pantanal, Estado de Mato Grosso do Sul. Os frutos obtidos foram transportados até a Unidade de Tecnologia de Alimentos e Saúde Pública (UTASP) da Universidade Federal de Mato Grosso do Sul, onde foram selecionados, higienizados e fracionados em casca, polpa e semente. A polpa foi processada em mixer Britânia ${ }^{\circledR}$ e congelada a $-20^{\circ}$ por processo lento, para a elaboração do frozen yogurt $\mathrm{e}$ análise posterior. Os ingredientes utilizados na elaboração do frozen yogurt foram: Leite UHT integral (Piracanjuba ${ }^{\varpi}$ ), iogurte natural integral $\left(\right.$ Batavo $\left.^{\oplus}\right)$, sacarose $\left(\right.$ Sonora $\left.{ }^{\circledast}\right)$, glicose, creme de leite (Itambé $\left.{ }^{\circledR}\right)$, estabilizante (Liga Neutra ${ }^{\circledast}$ ), emulsificante $\left(\right.$ Emustab $\left.^{\circledR}\right)$, fermento láctico probiótico liofilizado $\left(\right.$ BioRich $\left.^{\circledast}\right)$ e polpa concentrada de laranjinha de pacu. 


\section{Elaboração do iogurte}

O leite UHT integral, (4 litros), foi aquecido à temperatura de $90^{\circ} \mathrm{C}$, em seguida resfriado à temperatura de $42-43^{\circ} \mathrm{C}$, quando o iogurte natural, $850 \mathrm{~g}$, foi inoculado e homogeneizado. Após a inoculação, a mistura foi levada à estufa para fermentação, onde permaneceu a $42^{\circ} \mathrm{C}$ até atingir o valor de $\mathrm{pH}$ entre 4,5 - 4,7, em torno de 12 horas. O iogurte obtido foi mantido sob refrigeração para elaboração do frozen yogurt.

\section{Elaboração do frozen yogurt}

Primeiramente, a polpa de laranjinha de pacu foi concentrada por meio de calor seco, por 15 minutos, perdendo 31,9\% de água. À polpa, adicionou-se sacarose, glicose, creme de leite, emulsificante e estabilizante, homogeneizados e pasteurizados a $75^{\circ} \mathrm{C}$, por 15 minutos. Após o resfriamento à temperatura ambiente, adicionou-se o iogurte e o fermento láctico probiótico liofilizado, posteriormente à dissolução numa pequena quantidade de iogurte. As quantidades dos ingredientes utilizados na elaboração do frozen yogurt são mostrados na Tabela 1.

A mistura foi homogeneizada e, então, levada para a sorveteira (Finamac Arpifrio Pro $4^{\circledR}$ ), onde permaneceu sob contínua agitação até atingir a temperatura de $-5,9^{\circ} \mathrm{C}$. Após o batimento, o frozen yogurt foi envazado em potes para sorvete e armazenado em temperatura de congelamento a $-20^{\circ} \mathrm{C}$.

Tabela 1 - Ingredientes utilizados na elaboração do frozen yogurt.

\begin{tabular}{cc}
\hline Ingredientes & Quantidade (\%) \\
\hline Iogurte & 3500 \\
Sacarose & 625 \\
Polpa concentrada & 500 \\
Creme de leite & 300 \\
Glicose & 140 \\
Estabilizante & 50 \\
Emulsificante & 35 \\
Fermento láctico probiótico & 1 \\
\hline
\end{tabular}

\section{Análises físico-químicas}

Foram realizadas análises físico-químicas do frozen yogurt e da polpa de laranjinha de pacu, em triplicata, segundo metodologia oficial do Instituto Adolfo Lutz (BRASIL, 2005) e Association of Official Analytical Chemists (1995) para umidade, cinzas, proteínas, lipídios, açúcares totais, sólidos totais (Extrato Seco Total), pH e acidez titulável.

\section{Análise microbiológica}

As contagens das culturas probióticas no frozen yogurt foram realizadas em duplicata no $15^{\circ}$, $30^{\circ}$ e $60^{\circ}$ dias de estocagem do produto. Para a contagem de Lactobacillus acidophilus foi utilizado o meio MRS-ágar com $10 \%$ de solução de maltose $20 \%$, com incubação anaeróbica a $37^{\circ} \mathrm{C} / 72 \mathrm{~h}$ (INTERNATIONAL DAIRY FEDERATION, 1999). A contagem de Bifidobacterium sp. foi realizada em MRS - ágar com adição de 0,5\% de solução de dicloxacilina a 0,01\%,1,0\% de solução de cloreto de lítio a $11,11 \%$ e $0,5 \%$ de solução de cloreto de cisteína a $10 \%$, com incubação a anaeróbica a $37^{\circ} \mathrm{C} / 72 \mathrm{~h}$ (CHR HANSEN, 2007). 


\section{Análise sensorial}

A análise sensorial do frozen yogurt foi realizada no Centro de Ciência Biológicas e da Saúde da Universidade Federal de Mato Grosso do Sul, por meio de teste afetivo de aceitabilidade, utilizando-se escala hedônica de 9 pontos $(1$ = desgostei muitíssimo, 5 = nem gostei/nem desgostei e 9 = gostei muitíssimo) (DUTCOSKY, 2011).O teste foi conduzido em local centralizado com participação de 101 julgadores não treinados, que avaliaram o frozen yogurt quanto aos atributos: qualidade global, cor, aroma, textura e sabor. Cerca de $50 \mathrm{~g}$ do frozen yogurt foi oferecido em copos plásticos, à temperatura de $-5,0^{\circ} \mathrm{C}$.

O índice de aceitabilidade foi calculado por meio da fórmula: $L A(\%)=A \times 100 / B$, sendo $\mathrm{A}=$ nota média obtida para o produto; $\mathrm{B}$ = nota máxima dada ao produto (DUTCOSKY, 2011).

Este trabalho foi submetido ao Comitê de ética para pesquisa em seres humanos da Universidade Federal de Mato Grosso do Sul, e somente realizada a análise sensorial, após aprovação do protocolo referente ao Certificado de Apresentação para Apreciação Ética (CAAE) de no: 34016414.2.0000.0021, seguindo aos padrões exigidos pela Resolução 466 de 12 de dezembro de 2012 do Ministério da Saúde/ Conselho Nacional da Saúde. Foram considerados como critérios de exclusão: possuir sensibilidade a algum ingrediente da formulação do frozen yogurt de laranjinha de pacu, e aqueles que não aceitaram participar da pesquisa e/ou que não assinaram o Termo de Consentimento Livre e Esclarecido (TCLE).

\section{Análise estatística}

Os dados da composição físico-química da polpa do fruto e do frozen yogurt elaborado foram avaliados por análise de variância (ANOVA), com auxílio do software Statgraphics plus ${ }^{\circledR}$, versão 5.1, considerando-se nível de significância de 5\%.

\section{RESULTADOS E DISCUSSÃO}

\section{Análise físico-química}

Os resultados referentes às análises físico-químicas da polpa de laranjinha de pacu e do frozen yogurt apresentaram diferenças estatísticas em todos os parâmetros avaliados, com exceção do conteúdo de cinzas (Tabela 2).

Tabela 2 -Parâmetros físico-químicos da polpa de laranjinha de pacu e do frozen yogurt probióticode laranjinha de pacu (média \pm DP).

\begin{tabular}{ccc}
\hline Parâmetros físico-químicos & Polpa de laranjinha de pacu & Frozen yogurt \\
\hline Umidade (\%) & $85,22 \pm 0,28^{\mathrm{a}}$ & $73,52 \pm 0,03^{\mathrm{b}}$ \\
Extrato seco total (\%) & $14,78 \pm 0,28^{\mathrm{a}}$ & $26,48 \pm 0,03^{\mathrm{b}}$ \\
Lipídios (\%) & $0,32 \pm 0,05^{\mathrm{a}}$ & $6,0 \pm 0,01^{\mathrm{b}}$ \\
Proteínas (\%) & $0,69 \pm 0,26^{\mathrm{a}}$ & $2,97 \pm 0,02^{\mathrm{b}}$ \\
Glicídios totais (\%) & $10,93 \pm 0,07^{\mathrm{a}}$ & $16,38 \pm 0,71^{\mathrm{b}}$ \\
Cinzas (\%) & $0,64 \pm 0,06^{\mathrm{a}}$ & $0,69 \pm 0,01^{\mathrm{a}}$ \\
Acidez titulável(\%) & $4,94 \pm 0,37^{\mathrm{a}}$ & $1,18 \pm 0,02^{\mathrm{b}}$ \\
pH & $3,19 \pm 0,04^{\mathrm{a}}$ & $4,32 \pm 0,02^{\mathrm{b}}$ \\
\hline
\end{tabular}

Letras diferentes na mesma linha indicam diferença significativa pelo teste deTukey $(p<0,05)$. ${ }^{1}$ Expressoem \% deácido cítrico $(g / 100$ g) para a polpa de laranjinha de pacu eexpresso em \% de ácido láctico (g/100 g) para o frozen yogurt. 
A polpa de laranjinha de pacu apresentou alto teor de umidade e baixo conteúdo de proteína e lipídios. $\mathrm{O}$ teor de umidade apresenta-se superior ao encontrado em frutos do mesmo gênero, como o Abiu (Pouteria caimito Radlk.), 61 e 85,9\%, e o Mamey (Pouteria sapota Jacq.), que possuem $63,8 \%$ de umidade (LOVE, 2011; YAHIA, 2011). Os valores de glicídios $(10,93 \pm 0,07)$ apresentaram-se semelhante a outros frutos nativos do Pantanal e do Cerrado, como araçá e tarumã (CALDEIRA et al., 2004).

$\mathrm{O}$ pH da laranjinha de pacu foi superior ao encontrado por Ferreira (2015) de 2,9 e inferior em relação ao abiu (Pouteria caimito), fruto do mesmo gênero, encontrado na Floresta Amazônica. Apresentaram também teores semelhantes de umidade e de lipídios citados por Canuto e colaboradores (2010), caracterizando a laranjinha como uma fruta muito ácida. De acordo com Lima e colaboradores (2013), o pH interfere beneficamente em diversos aspectosdo fruto, como retenção do sabor-odor de produtos de frutos, tempo de deterioração, temperatura de tratamento, verificação do estágio de maturação, escolha da embalagem, equipamentos utilizados, aditivos, conservantes e na palatabilidade.

Os padrões de identidade e qualidade de gelados comestíveis, os quais incluem o frozen yogurt, são regulamentados pela Resolução RDC no .266 , de 22 de setembro de 2005, da Agência Nacional de Vigilância Sanitária (ANVISA). O teor de extrato seco total do frozen yogurt (26,48 $\pm 0,03 \%)$, o conteúdo proteico obtido $(2,97 \pm 0,02 \%)$ e lipídico $(6,00 \pm 0,01)$ estão de acordo com a legislação vigente, a qual exige um mínimo de $26 \%$ de sólidos totais, e de 2,5\% de proteínas (ANVISA, 2005). Esses valores são semelhantes aos encontrados por Alves e colaboradores (2009), que obtiveram $26,6 \%$ de sólidos totais e $3 \%$ de proteínas para frozen yogurt à base de leite de cabra acrescido de culturas probióticas. $\mathrm{O}$ teor de proteínas foi maior do que os valores reportados por Gonçalves e Eberle (2008) - 2,43\% - para frozen yogurt à base de leite de vaca também adicionado de culturas probióticas. Além disso, o conteúdo de gorduras também atende ao mínimo estabelecido (2,5\%) (BRASIL, 2005), proporcionando textura mais macia e cremosa, bem como sabor mais acentuado, resultando em característica sensoriais mais favorecidas de um modo geral (GUINARD et al., 1994).

Até o momento não existe regulamentação que estabeleça o nível mínimo de acidez e pH para gelados comestíveis. $\mathrm{O}$ valor de $\mathrm{pH}$ encontrado $(4,32 \pm 0,02)$ está próximo do encontrado por Pinto (2012) em frozen yogurt com Bifidobacterium BB-12 microencapsulada. O valor de acidez titulável encontrado para frozen yogurts com pH entre 4,2 e 4,5 foi em torno de 0,7 e 0,8\% de ácido láctico (GONÇALVES; EBERLE, 2008; PEREIRA et al., 2012). Portanto, o valor obtido $(1,18 \pm 0,02 \%)$ está acima do que geralmente é encontrado, possivelmente devido à alta acidez da polpa de laranjinha $(4,94 \pm 0,37)$ utilizada na elaboração do frozen yogurt.

\section{Análise microbiológica}

Durante a estocagem, pôde-se observar uma diminuição do número de células viáveis. Com 30 dias de estocagem, o frozen yogurt de laranjinha de pacu apresentou contagem de

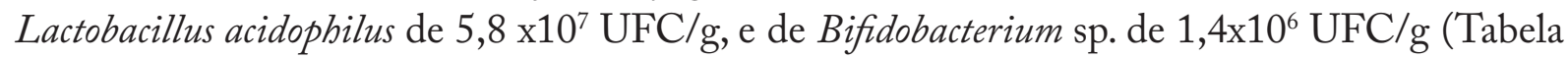
3). Durante o armazenamento, a acidificação do produto final, o nível de oxigênio no produto e a permeação do oxigênio através da embalagem podem reduzir a viabilidade das culturas probióticas, principalmente das bifidobactérias que são anaeróbias (GONÇALVES; EBERLE, 2008). 
Tabela 3 -Contagem (UFC/g) de Lactobacillus acidophilus e Bifidobacterium sp. em frozen yogur tprobiótico de laranjinha de pacu após estocagem em temperatura inferior $\mathrm{a}-18^{\circ} \mathrm{C}$.

\begin{tabular}{ccc}
\hline Tempo de estocagem (dias) & Lactobacillus acidophilus & Bifidobacterium sp. \\
\hline 15 & $9,2 \times 10^{7}$ & $9,2 \times 10^{6}$ \\
30 & $5,8 \times 10^{7}$ & $1,4 \times 10^{6}$ \\
60 & $1,5 \times 10^{7}$ & $8,2 \times 10^{5}$ \\
\hline
\end{tabular}

Apesar dessa diminuição durante o armazenamento, vale ressaltar que segundo a lista de alegações de propriedade funcional aprovadas pela Comissão Tecnocientífica de Assessoramento em Alimentos Funcionais e Novos Alimentos da ANVISA, a quantidade mínima viável para os probióticos deve estar situada na faixa de $10^{8}$ a $10^{9}$ UFC na recomendação diária do produto pronto para o consumo até o final prazo de validade, conforme indicação do fabricante (ANVISA, 2008). Isso corresponderia ao consumo diário de 200 a $400 \mathrm{~g}$ desses produtos contendo $10^{6} \mathrm{UFC} / \mathrm{g}$ das cepas probióticas declaradas. Segundo alguns estudos, esta é a concentração mínima necessária de bactérias probióticas no produto, para que este exerça um efeito benéfico ao organismo (KOMATSU; BURITI; SAAD, 2008; BARRETO et al., 2003). Dessa forma, o frozen yogurt elaborado possui características probióticas, visto que apresentou a quantidade mínima de microorganismos viáveis necessários mesmo após a estocagem.

Estudos vêm apontando importantes funções desempenhadas por bactérias probióticas à saúde do hospedeiro. De modo geral, as bactérias que produzem ácido láctico geram boas quantidades de Interleucina-10 (IL-10), citocina anti-inflamatória que atua de forma positiva no sistema imunológico da mucosa intestinal e no controle geral da inflamação (SANZ; SANTACRUZ; GAUFFIN, 2010). Além disso, o gênero Pouteria apresenta-se como uma ótima alternativa de consumo para benefícios à saúde, devido a atividades biológicas importantes associadas, como função anti-inflamatória e potencial ação antioxidante (SILVA; SIMEONI; SILVEIRA, 2009).

\section{Análise sensorial}

O frozen yogurt probiótico de laranjinha de pacu obteve boa aceitação geral, visto que todos os atributos avaliados (cor, sabor, aroma, textura e qualidade global) apresentaram notas médias entre 7 (gostei ligeiramente) e 8 (gostei muito), que equivale à alternativa "gostei moderamente" (Tabela 4).

Tabela 4 - Média das notas de diferentes atributos sensoriais de frozenyogurt probiótico de laranjinha de pacu $(n=101)$.

\begin{tabular}{ccc}
\hline Atributos & Notas $^{\mathbf{1}}(\mathbf{m e ́ d i a} \pm \mathbf{D P})$ & IA\% $^{\mathbf{2}}$ \\
\hline Qualidade global & $7,97 \pm 0,77$ & 88,56 \\
Cor & $8,13 \pm 1,05$ & 90,32 \\
Aroma & $7,52 \pm 1,27$ & 83,61 \\
Sabor & $7,89 \pm 1,33$ & 87,68 \\
Textura & $7,76 \pm 1,23$ & 86,25 \\
\hline
\end{tabular}

${ }^{1}$ Equivalênciadenotas:desgosteimuitíssimo $=1$, desgosteimuito $=2$, desgosteiregularmente $=3$, desgosteiligeiramente $=4$, indiferente $=5$, gostei regularmente $=6$, gostei ligeiramente $=7$, gostei muito $=8$ e gostei muitíssimo $=9$. Í́ndice de Aceitabilidade . 
Um dos aspectos fundamentais na qualidade e aceitabilidade do produto refere-se à cor que é obtida através de pigmentos naturais existente no alimento ou pela adição de corantes. $\mathrm{O}$ uso da polpa de laranjinha de pacu forneceu ao frozen yogurt uma cor natural e característica, o que lhe conferiu nota acima de 8 (gostei muito).

Segundo Pereira (2012), frozen yogurt com pH entre 5,0 e 5,5 apresenta maior aceitabilidade em análise sensorial. Entretanto, o $\mathrm{pH}$ do frozen yogurt elaborado não prejudicou o aroma e o sabor do produto, visto que a média das notas obtidas para esses atributos ficaram acima de 7 na escala hedônica e o índice de aceitabilidade manteve-se entre $80 \%$ e $90 \%$, que é consideradocomo boa aceitação do produto, de acordo com Monteiro (1984) e Dutcosky (2011), desde que seja acima de $70 \%$. Além disso, o uso de probióticos, bem como a fermentação láctica do leite, influencia diretamente no sabor e aroma, em decorrência dos produtos resultantes do metabolismo dos micro-organismos da cultura láctica (BESSA, 2014).

\section{CONCLUSÃO}

O produto elaborado respeitou os teores de sólidos totais, proteínas e gordura preconizados pela legislação vigente para gelados comestíveis, além de constituir-se em um alimento probiótico, que, mesmo após a estocagem de 30 dias, apresentou a quantidade mínima de micro-organismos viáveis necessários, caracterizando-se como um produto com alto valor nutricional e funcional, visto que o probiótico atua no controle de bactérias patogênicas entéricas e no sistema imune como um todo. Além disso, obteve índice de aceitabilidade acima de 80\%, representando boa aceitação quanto aos seus atributos sensoriais.

Dessa forma, pode-se considerar que bactérias probióticas aliadas à laranjinha de pacu no frozen yogurt representam um alimento funcional que possui altas expectativas de aceitação no mercado, aliando a valorização de frutos nativos e preservação das suas áreas de ocorrência.

\section{REFERÊNCIAS}

ALMEIDA, M.M.B.; SOUZA, P.H.M.; ARRIAGA, A.M.C.; PRADO, G.M.P.; MAGALHÃES, E.C.; MAIS, G.A.M.; de LEMOS, T.L.G. Bioactive compounds and antioxidant activity of fresh exotic fruits from northeastern Brazil. Food Research International, v. 44 n. 7, p. 2155-2159, 2011.

ALVES, L.L.; RICHARDS, N.S.P.S.; BECKER, L.V.; ANDRADE, D.F.; MILANI, L.I.G.;REZER, A.P.S.; SCIPIONI, G.C. Aceitação sensorial e caracterização de frozen yogurt de leite de cabra com adição de cultura probiótica e prebiótico. Ciência rural, v. 39, n. 9, p.2595-2600, 2009.

ASSOCIATION OF OFFICIAL ANALYTICAL CHEMISTS. Official methods of analysis. 16. ed. Washington (AOAC): 1995.

BARRETO, G.P.M.; SILVA, N.; SILVA, E.N.; BOTELHO, L.; YIM,D.K.; ALMEIDA, C.G.; SABA,G.L. Quantificação de Lactobacillusacidophilus, bifidobactérias e bactérias totais em produtos comercializados no Brasil. Brazilian Journalof Food Technology, v.6, n.1, p. 119-126, 2003. 
BESSA, M.E. Percepção sensorial e aceitação do leite de cabra fermentado. 2014. 121 f. Dissertação (Mestrado Profissional em Ciência e Tecnologia do Leite e Derivados) Faculdade de Farmácia e Bioquímica, Universidade Federal de Juiz de Fora, Juiz de Fora, 2014.

ANVISA. Agência Nacional de Vigilância Sanitária. Resolução RDC n. 266 de 22 de setembro de 2005. Regulamento técnico para fixação de identidade e qualidade de gelados comestíveis e, preparados para gelados comestíveis, pós para o preparo e bases para gelados comestíveis. Diário Oficial da União, 23 set. 2005b. Disponível em: $<$ http://portal.anvisa.gov.br/wps/wcm/connect/f5d552004a9bdc469832dc4600696f00/ Resolucao_RDC_n_266_de_22_de_setembro_de_2005.pdf?MOD=AJPERES $>$.Acesso em 01 nov. 2014.

BRASIL. Ministério da Saúde. Agência Nacional de Vigilância Sanitária. Métodos físico-químicos para análise de alimentos. 4. ed. Brasília: Ministério da Saúde, 2005.

ANVISA. Agência Nacional de Vigilância Sanitária. Comissões e Grupos de Trabalho. Comissão Tecnocientífica de Assessoramento em Alimentos Funcionais e Novos Alimentos. Alimentos com alegações de propriedades funcionais e ou de saúde, novos alimentos/ingredientes, substâncias bioativas e probiótios. IX - Lista de alegações de propriedade funcional aprovadas. Atualizado em julho, 2008. Disponível em: <http:// www.anvisa.gov.br/alimentos/comissoes/tecno_lista_alega.htm>. Acesso em 01 nov. 2014.

CALDEIRA, S.D.; HIANE, P.A.; RAMOS, M.I.L.; RAMOS FILHO,M.M. Caracterização físico-química do araçá (Psidium Guineense SW.) e do tarumã (VitexCymosaBert.) do estado de Mato Grosso do Sul. Boletim do Centro de Pesquisa de Processamento de Alimentos, v. 22, n.1, p. 145-154, 2004.

CANUTO, G.A.B.; XAVIER, A.A.O.; NEVES, L.C.; BENASSI,M.T. Caracterização físico-química de polpas de frutos da Amazônia e sua correlação com a atividade antiradical livre. Revista Brasileira de Fruticultura, v. 32, n. 4, p. 1196-1205, 2010.

CARDOSO, L.M.; MARTINO, H.S.D.; MOREITA, A.V.B.; RIBEIRO, S.M.R.; SANT'ANA, H.M.P. Cagaita (Eugenia Dysenterica DC.) of the Cerrado of Minas Gerais, Brazil: physical and chemical characterization, carotenoids and vitamins. Food Research International, v. 44 n. 7, p. 2151-2154, 2011.

CHR HANSEN. Bifidobacteria Enumeration ABC Alternative Method for Enumeration of Bifidobacteria in Fermented Milk Products.Denmark: Chr. Hansen A/S, 2007. (Technical Bulletin, n. 12).

CORTE,F.F.D. Desenvolvimento de frozenyogurt com propriedades funcionais. 2008. 97 f. Dissertação (Mestrado em Ciência e Tecnologia de Alimentos), Universidade Federal deSanta Maria, Santa Maria, 2008. 
DAMASCENO JUNIOR, G.A.; SOUZA, P.R.; IBORTOLOTTO, I.M.; BRAGA NETO, J.A.; COSTA, D.C.; RAMOS,M.I.L.;et al. Sabores do Cerrado e Pantanal: receitas e boas práticas de aproveitamento. 1. ed. Campo Grande: UFMS; 2010.p.81-82.

DUTCOSKY, S.D. Análise Sensorial de Alimentos. 3. ed. Curitiba: Champagnat; 2011

DUTCOSKY, S. D. Análise sensorial de alimentos.Curitiba: 2. ed. Champagnat; 2007.

FERREIRA, C. M.; VIEIRA, A. T.; VINOLO, M. A. R.; OLIVEIRA, F. A.; CURI, R.; MARTINS, F. D. S. The Central Role of the Gut Microbiota in Chronic Inflammatory Diseases. Journal of Immunology Research, 2014, 689492, 2014.

FERREIRA,J.A. Caracterização química da laranjinha-de-pacu (Pouteriaglomerata) (miq.) radlq.) e elaboração de sorvete. 2015. 75 f. Dissertação (Mestrado em Saúde e Desenvolvimento na Região Centro-Oeste) - Faculdade Medicina, Universidade Federal de Mato Grosso do Sul, Campo Grande, 2015.

GONÇALVES, A.A.; EBERLE,I.R. Frozenyogurt com bactérias probióticas. Alimentos e Nutrição, v. 19, n. 3, p. 291-297, 2008.

GUINARD J.X.; LITTLE, C.; MARTY, C.; PALCHAK, T.R. Effect of sugar and acid on the acceptability of frozen yogurt to a student population. Journal of Dairy Science, v. 77, n. 5 , p. 1232-1238, 1994.

GUL, K.; SINGH, A.K.; JABEEN, R. Nutraceuticals and Functional Foods: The Foods for the Future World. Critical Reviews in Food Science and Nutrition, v. 56, n.16, p. 2617-2627, 2016.

HEMARAJATA, P.; VERSALOVIC,J. Effects of probiotics on gut microbiota: mechanisms of intestinal immunomodulation and neuromodulation. Therapeutic Advances in Gastroenterology, v. 6, p.39-51, 2013.

INTERNATIONAL DAIRY FEDERATION. Detection and enumeration of Lactobacillus acidophilus. Bruxelas, Bélgica. Bulletin of the IDF, n.306, p.23-33, 1999.

KOMATSU,T.R.; BURITI, F.C.L.; SAAD, S.M.I. Inovação, persistência e criatividade superando barreiras no desenvolvimento de alimentos probióticos. Revista Brasileira de Ciências Farmacêuticas, v. 44, n. 3, p. 329-347, 2008.

LIMA, C.A.; FALEIRO, F.G.; JUNQUEIRA, N.T.V.; COHEN, K.O.; GUIMARÃES, T.G. Physico-chemical characteristics, polyphenols and yellow flavonoids in fruits of commercial and wild pitaya species from the Brazilian savannas. Revista Brasileira de Fruticultura, v. 35, n.2, p. 565-570, 2013. 
LOVE, K.; PAULL, R.E. ABIU. College of Tropical Agriculture and Human Resources.

Fruits and Nuts, n.24, p.1 -6, 2011.

MITSUOKA,T. Developmentoffunctionalfoods. Bioscience of Microbiota, Food and Health, v. 33, p. 117-128, 2014.

MONTEIRO, C. L. B. Técnicas de avaliação sensorial.2. ed., Curitiba: CEPPA-UFPR; 1984.

OLIVEIRA, KAM., RIBEIRO, LS., OLIVEIRA, GV., PEREIRA, JMATK., MENDONÇA, RCS., ASSUMPÇÃO, CF. Desenvolvimento de formulação de iogurte de Araticum e estudo da aceitação sensorial. Alimentos e Nutrição Araraquara, v. 19,n. 3, p. 277-281, 2008.

PEREIRA,G.G.;RAFAEL,L.M.; GAJO,A.A.; RAMOS,T.M.;PINTO, S.M.; ABREU, L.R.; RESENDE, J.V. Influência do $\mathrm{pH}$ nas características físico-químicas e sensoriais de frozenyogurt de morango. Semina: Ciências Agrárias, n. 33, n. 2, p. 675-686, 2012.

PINTO, S.S. Efeito da adição de Bifidobacterium BB-12 micro encapsulada sobre as propriedades de frozen iogurte.2012. 145 f. Dissertação (Mestrado em Ciência dos Alimentos) - Centro de Ciências Agrárias, Universidade Federal de Santa Catarina, Florianópolis, 2012.

POTT, A.; POTT,V.J.Plantas do Pantanal. Brasília: EMBRAPA; 1994.

ROBERFROID M, GIBSON GR, HOYLES L, MCCARTNEY AL, RASTALL R, ROWLAND I, WOLVERS D, WATZL B, SZAJEWSKA H, STAHL B, GUARNER F, RESPONDEK F, WHELAN K, COXAM V, DAVICCO MJ, LÉOTOING L, WITTRANT Y, DELZENNE NM, CANI PD, NEYRINCK AM, MEHEUST A. Prebioticeffects: metabolicandhealthbenefits. British Journal of Nutrition, v. 104, n. 2, p. 1-63, 2010.

ROCHA, C.; COBUCCI, R.M.; MAITAN, V.R.; SILVA, O.C. Elaboração e avaliação de iogurte sabor frutos do Cerrado. Boletim do Centro de Pesquisa de Processamento de Alimentos, v. 26, n. 2, p. 255-266, 2008.

ROSS, R.P.; DESMOND, C.; FITZGERALD, G.F.; STANTON, C. Overcoming the technological hurdles in the development of probiotic foods. Journal of Applied Microbiology, v. 98, n. 6, p. 1410-1417, 2005.

SANZ, Y.; SANTACRUZ, A.; GAUFFIN,P. Session 8: Probiotics in the defence and metabolic balance of the organism. Gut microbiota in obesity and metabolic disorders. Proceedings Of The Nutrition Society, v. 69, n.3, p. 434-441, 2010. 
SHARIF, H. R.; WILLIAMS, P. A.; SHARIF, M. K., ABBAS; S., MAJEED, H.; MASAMBA, K. G.; ... ZHONG, F. Current progress in the utilization of native and modified legume proteins as emulsifiers and encapsulants - A review. Food Hydrocolloids, v.76, p. 2-16, 2018.

SOUSA, F.C.; SILVA,L.M.M.; SOUSA, E.P.; LIMA,A.K.V.O.; FIGUEIREDO, R.M.F. Parâmetros físicos e físico-químicos da polpa de pequi. Revista Verde de Agroecologia e Desenvolvimento Sustentável, v. 6, n. 1, p. 12-15, 2012.

VIDAL, A.M.; DIAS, D.O.; MARTINS, E.S.M.; OLIVEIRA, R.S.; NASCIMENTO, R.M.S.; CORREIA, M.G.S. A Ingestão de Alimentos Funcionais e sua contribuição para a diminuição da Incidência de doenças. Caderno de Graduação - Ciências Biológicas e da Saúde, v. 1, n. 15, p. 43-52, 2012.

YAHIA, E.M.; GUTIÉRREZ -OROZCO, F. Mamey sapote (Pouteria sapota Jacq. H. E. Moore \& Stearn). In: Postharvest biology y and technology of tropical and subtropical fruits. Editor: Yahia, E.M. Woodhead Publishing Limited, v. 3, p. 482 -491, 2011. 